\title{
Regularities of changes in the properties of multilayer polymer films depending on their structure
}

\author{
(C) Valentina N. Serova, ${ }^{*+}$ and Iskander I. Muratov \\ Kazan National Research Technological University. \\ K. Marx St., 68. Kazan, 420015. Russia.E-mail: vnserova@rambler.ru
}

\begin{abstract}
*Supervising author; ${ }^{+}$Corresponding author
Keywords: multilayer polymer films, destructive tensile stress, modulus of elasticity, resistance to delamination of the weld, spectral transmittance, optical density, light resistance, gas permeability.
\end{abstract}

\section{Abstract}

The physical-mechanical, optical and operational properties of three types of multilayer polymer films that are used in the manufacture of laminates for food packaging and differ in the composition and number of layers (from 3 to 9) are studied: transparent based on high-pressure polyethylene; white (containing a white pigment) on the basis of high pressure polyethylene; transparent barrier based on high-pressure polyethylene, polyamide and ethylene copolymer with vinyl alcohol. For comparison, we also used a single-layer film made of high-pressure polyethylene.

The films were tested for tensile strength, resistance to delamination of the welded joint, spectral transmittance, optical density, differential scanning calorimetry curves were registered, and gas permeability was determined. To assess the light aging, the film samples were irradiated with a source of ultraviolet light. The following regularities are revealed: the tensile strength of the studied films does not differ significantly, both when changing their composition and the number of layers; a threefold increase in the number of layers leads to a noticeable increase in the elastic modulus of films made of high-pressure polyethylene with a white pigment; barrier film has a higher modulus of elasticity than transparent films based on high-pressure polyethylene; the resistance to delamination of the welded joint increases in the presence of high-pressure polyethylene films with the same number of layers of white pigment and increasing their thickness; increasing the number of layers leads to a decrease in the spectral transmittance and light resistance of transparent films, but does not affect this indicator of films with white pigment; the role of white pigment as an ultraviolet light absorber causes the greatest light resistance of films and its lesser dependence on the number of layers; barrier film in terms of light transmission and resistance to light aging is inferior to transparent films based on highpressure polyethylene, but it is significantly superior to a single-layer film; the gas permeability of barrier films naturally decreases with increasing thickness, and after light aging significantly increases due to photooxidative degradation of polymer layers and, to a greater extent, the layer of ethylene with vinyl alcohol copolymer.

\section{References}

[1] N. Zakrutchenko. Flexible films in the food packaging market. The meat of the matter. 2012. No.5. P.1415. (russian)

[2] V.N. Serova, D.V. Sugonyako, M.L. Verizhnikov, A.A. Tuftin. Performance properties of mono-and multi-layer polymer packaging films. Plastics. 2014. No.5-6. P.54-56. (russian)

[3] V.N. Serova, D.V. Sugonyako, M.L. Verizhnikov, A.A. Tuftin. Light Resistance and other comparative properties of polymer films for food packaging. Bulletin of Kazan technological University. 2014. Vol.17. No.3. P.104-107. (russian)

[4] V.N. Serova, S.A. Shevtsova, D.V. Sugonyako, A.A. Tuftin, M.L. Verizhnikov. Influence of aluminum oxide nanocoating on the properties of polyethylene terephthalate film and printing applied to it. Glues. Sealants. Technologies. 2015. No.8. P.36-41. (russian)

[5] V.N. Serova, E.N. Noskova. Optical characteristics and light resistance of polymer packaging films and their applied colorful layers. Bulletin of Kazan technological University. 2016. Vol.19. No.15. P.61-63. (russian)

[6] V.N. Serova, E.R. Mirkhusainov, J.Y. Gurkina, A.I. Khasanov. Quality paint coatings for polymeric packaging films. Glues. Sealants. Technologies. 2017. No.8. P.42-47. (russian) 
REGULARITIES OF CHANGES IN THE PROPERTIES OF MULTILAYER POLYMER FILMS...

[7] V.N. Serova, E.R. Mirkhusainov, A.I. Zagidullin, A.I. Khasanov, R.M. Garipov. Comparative characteristics of colorful coatings on mono - and multi-layer polymer film. Glues. Sealants. Technologies. 2017. No.12. P.37-40. (russian)

[8] V.N. Serova, E.R. Mirkhusainov. Comparative aging characteristics of polymer mono- and multilayer films based on polyamide. Plastics. 2018. No.3-4. P.56-58. (russian)

[9] V.N. Serova, A.I. Zagidullin. Thermal shrinkage of polymer packaging films and its influence on the quality of applied paint coatings. Glues. Sealants. Technologies. 2019. No.1. P.37-42. (russian)

[10] Bengt G. Ranby, Jan F. Rabek. Photodegradation, photo-oxidation, and photostabilization of polymers. London, New York: Wiley. 1975. 573p. 